\title{
Atomic Force Microscope: Enhanced Sensitivity
}

Donald T. Davis

Lawrence Livermore National Laboratory

Livermore, California

June, 1995

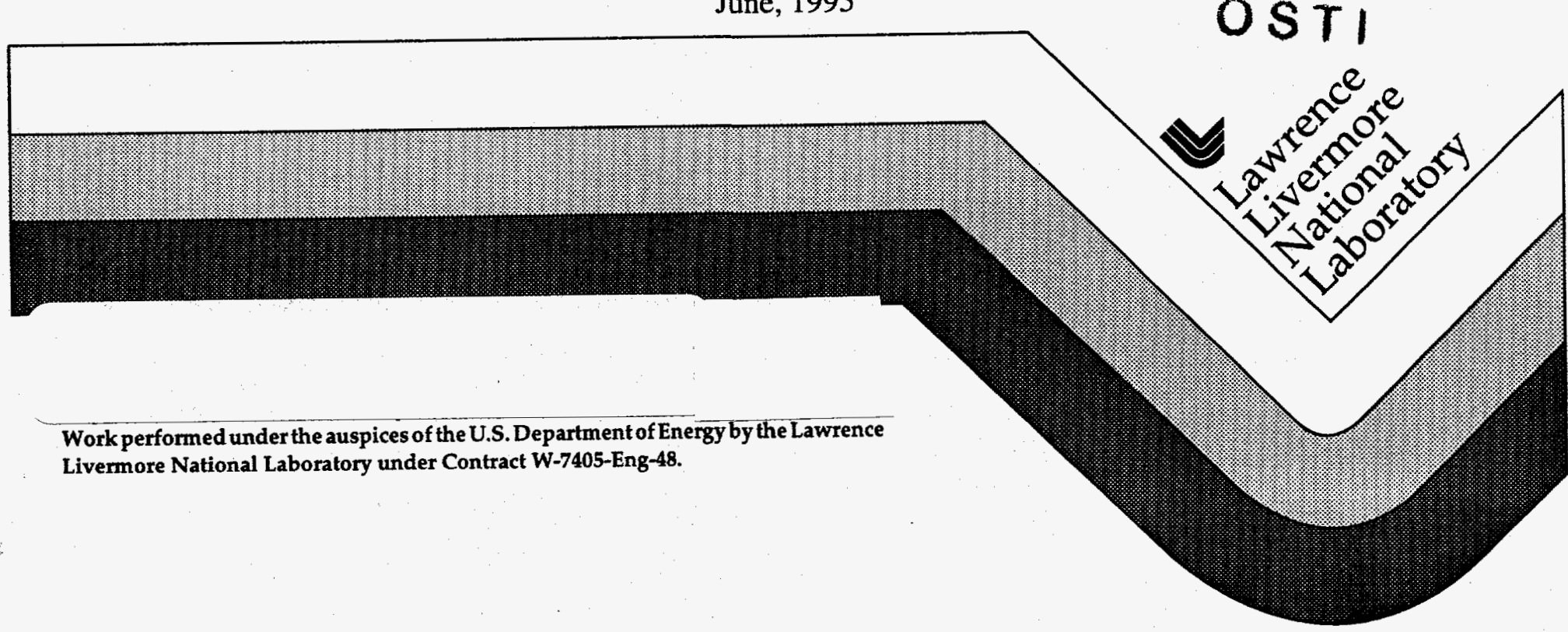




\section{DISCLAIMER}

This report was prepared as an account of work sponsored by an agency of the United States Government. Neither the United States Government nor any agency thereof, nor any of their employees, make any warranty, express or implied, or assumes any legal liability or responsibility for the accuracy, completeness, or usefulness of any information, apparatus, product, or process disclosed, or represents that its use would not infringe privately owned rights. Reference herein to any specific commercial product, process, or service by trade name, trademark, manufacturer, or otherwise does not necessarily constitute or imply its endorsement, recommendation, or favoring by the United States Government or any agency thereof. The views and opinions of authors expressed herein do not necessarily state or reflect those of the United States Government or any agency thereof. 


\section{DISCLAIMER}

Portions of this document may be illegible in electronic image products. Images are produced from the best available original document. 


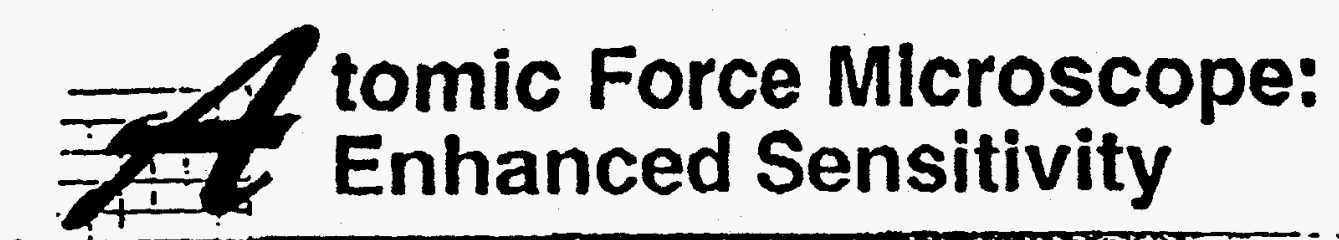

D. T. Davis

\section{3-SR-038}

Atomic force microscopes (AFMs) are a recent development representing the state of the art in measuring ultrafine surface features. Applications are found in such fields of research as biology, microfabrication, material studies, and surface chemistry. Fiber-optic interferometer techniques developed at LLNL offer the potential of improving the vertical resolution of these instruments by up to 2 orders of magnitude. We are attempting to replace the current AFM measurement scheme, which consists of an optical beam deflection approach, with our fiber-optic interferometer scheme (Fig. 1), a much more sensitive displacement measurement technique. In performing this research, we hope to accomplish two important goals; (1) to enhance the sensitivity of the AFM, and (2) to achieve important improvements in our fiber-optic interferometer technology.

In 1993, our efforts were directed toward increasing the sensitivity of our fiber-optic interferometer by reducing noise. We evaluated two approaches to reduce the main-noise-term, laser-amplitude fluctuations: (1) introduction of feedback to the laser-diode drive to sero its amplitude, and (2) electronic compensation of the common mode noise in the signal and laser amplitude.

The laser-amplitude servo approach (see Fig. 2) resulted in near shot-noise-limited operation (the lowest noise possible) but was restricted to frequencies above $100 \mathrm{~Hz}$. (see Fig. 3) For lower-frequency AFM applications, the common-mode-noise compensation scheme (see Fig. 4) must be used. Good higher-frequency results were also obtained with this technique, (see Fig. 5) but $1 / f$ noise at the lowest frequencies must now be reduced. We are investigating the use of a lownoise He-Ne laser with optical feedback isolator as well as mechanical isolation of the interferometer from structure-borne vibrations and airbome acoustic noises, so we can minimize these low-frequency noise and thus achieve interferometer sensitivity near the theoretical limit.
We also determined the theoretical limit of sensitivity imposed by both shot noise (see Fig. 6) from our laser source and Brownian (thermal) motion of the AFM measurement probe. (see Fig. 7) Both limits are well below the current AFM state of the art.

We plan to adapt our improved interferometer to a prototype AFM. We will pursue four main tasks; (1) to select and acquire a suitable AFM; (2) to develop passive and active vibration isolation and acoustic shielding for the instrument; (3) to design, fabricate, and install the interferometer, including enhanced $\mathrm{Q}$, bias control, and mechanical fixtures; and (4) to develop an AFM probe beam design with a highreflectivity coating and the appropriate geometry and spring constant. We will also demonstrate enhanced AFM sensitivity in an appropriate experiment.

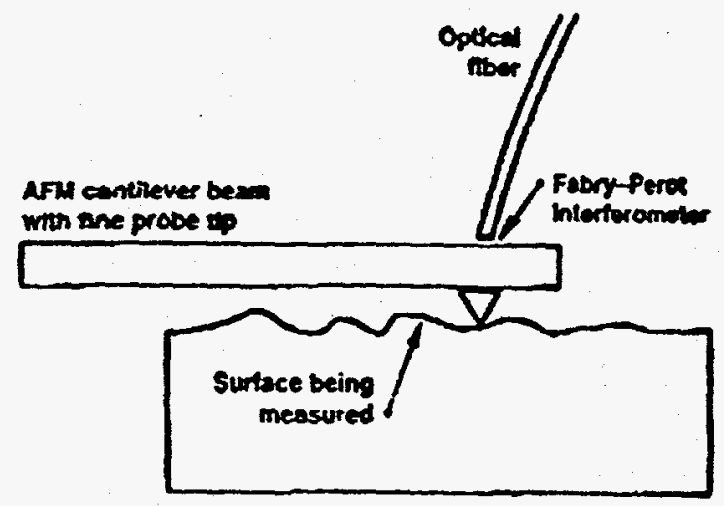

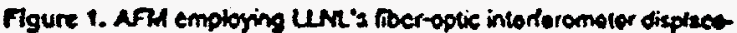
ment measuremal soleme. 


\section{We have developed a laser amplitude servo to reduce system noise}

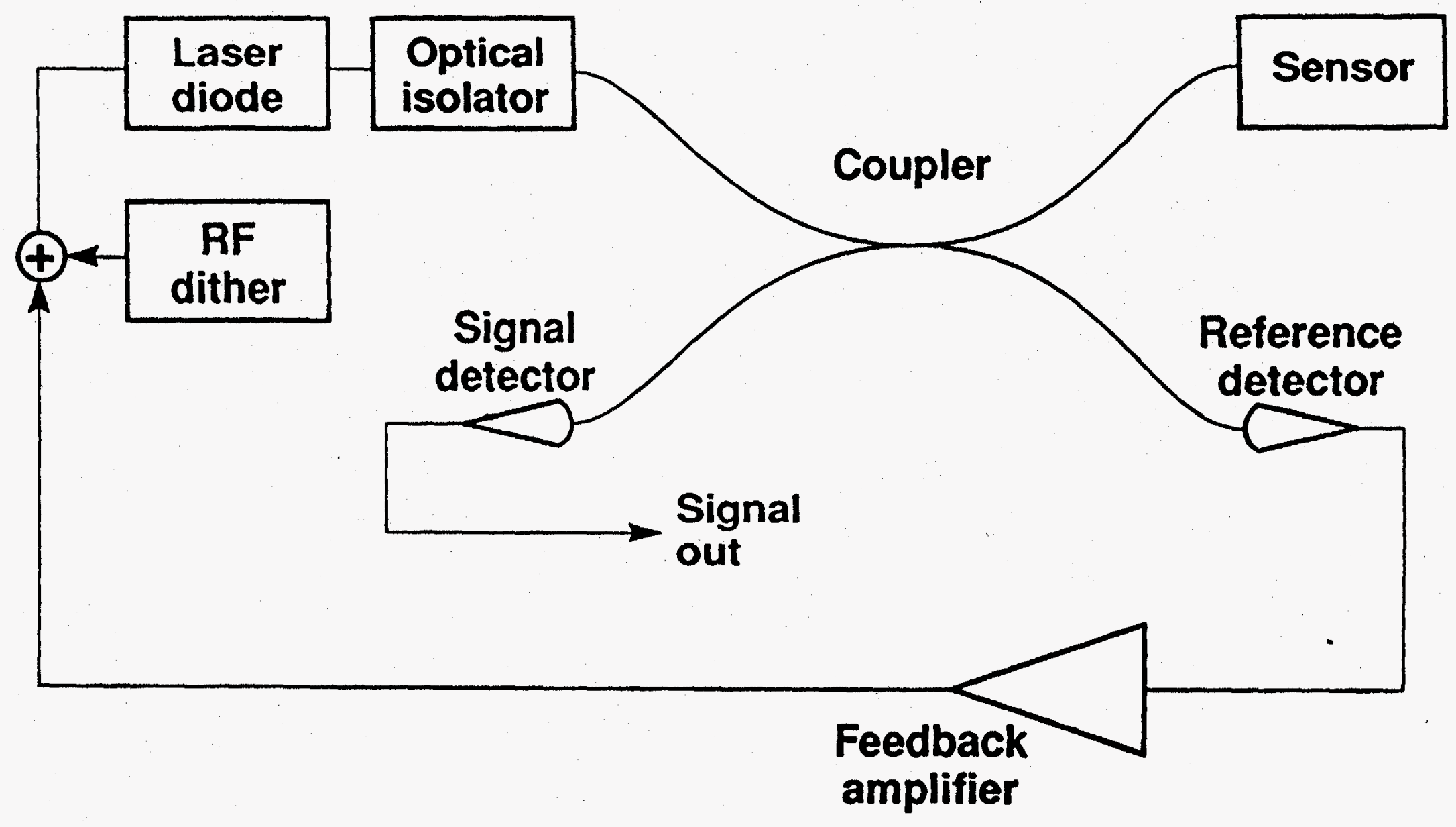




\section{Our feedback circuit reduces the laser noise down to the minimum level}

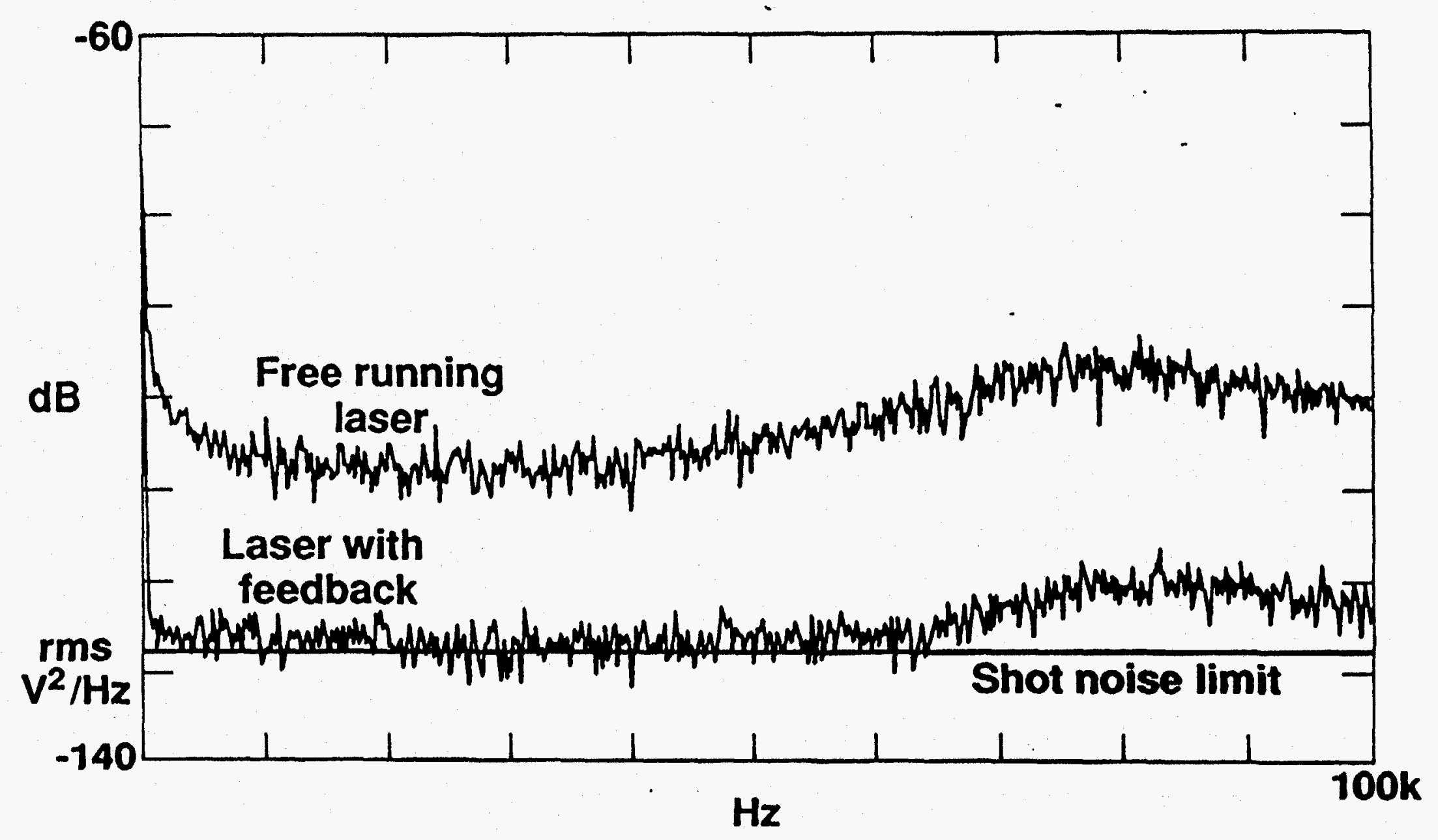




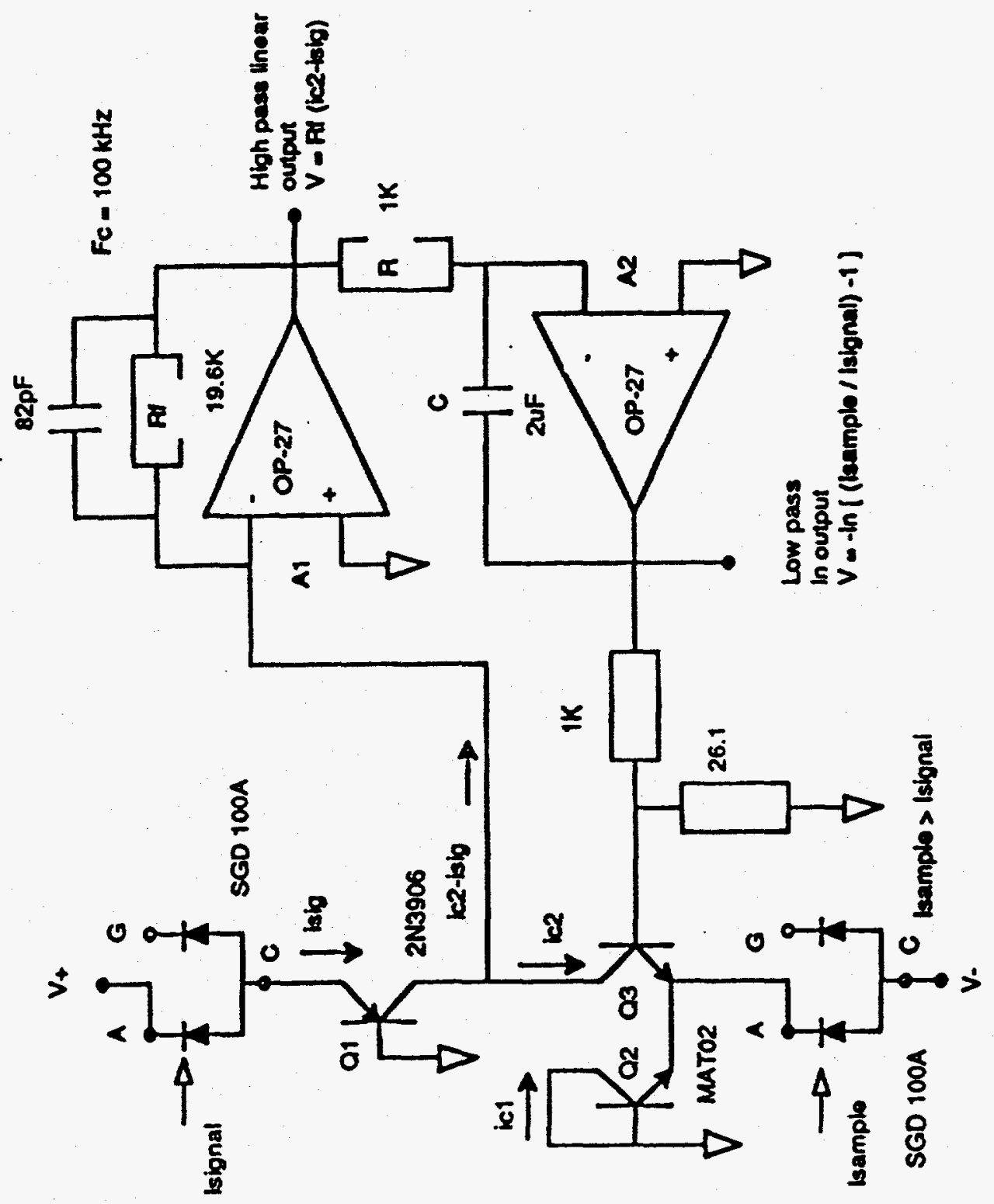


$X=120 \mathrm{~Hz}$

$Y_{\theta}=100.05$ dB

POWEA SPEC 1

$Y B=-B O \cdot 197 \mathrm{~dB}$

POWER SPEC 1

-EO.O

$-\mathbf{E O} .0$

$10 \mathrm{db} / \mathrm{div}$

dB -80

$\therefore \quad r m s$

$\mathrm{V} / \mathrm{SHz}$

dB

rms

$\mathrm{V} / \mathrm{rHz}$

$-140$

$-140$

Fxd Y O
Noirie Cuncelke

10AVg O\%OVIP Hann

10AVg OxOVIp Hann 


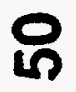

II

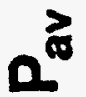

$\pi$

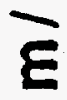

E

웅

6

$\frac{5}{3}$

- In

ต

क)

ว

()

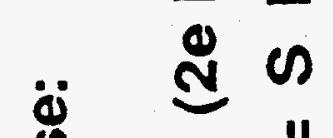

$\frac{n}{2}$

$\begin{array}{lll}\frac{0}{0} & 11 \\ z & = & =\end{array}$

‥ 김

용

II II

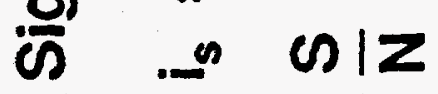


The cantilever beam must be effectively clamped to avoid Brownian motion

- Modeled as a mass/spring system with equi-partition of the thermal energy, we obtain-

$$
\begin{aligned}
& \frac{1}{2} K \overline{x^{2}}=\frac{1}{2} k T \text {, and } \\
& \bar{x}=(k T / K)^{\frac{1}{2}}\left(6 \times 10^{\prime \prime \prime} \mathrm{m} \text { for } K=1 \mathrm{~N} / \mathrm{m}\right)
\end{aligned}
$$

$\therefore$ Want the sample spring constant to be stiffer than the cantilever's to minimize Brownian motion

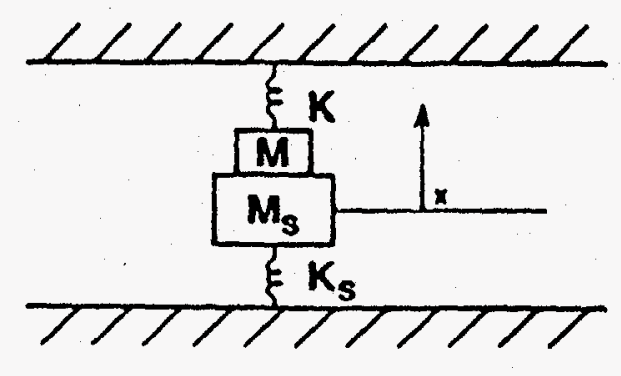

